\title{
IMAGENS, SONS E SILÊNCIO: O SENTIDO DE EXPERIÊNCIA NA PRÁTICA DO TEATRO DE SOMBRAS
}

\author{
Emerson Cardoso Nascimento 1 \\ Instituto Federal de Santa Catarina
}

Cremilson Oliveira Ramos 2

Instituto Federal de Santa Catarina

Há espaço para o silêncio em nosso mundo contemporâneo?

(Andréia Bonfim Perdigão)

Este artigo analisa as oficinas ${ }^{3}$ de teatro de sombras desenvolvidas com educadores na cidade de Imbituba - SC, no período de 4 de maio a 28 de julho de 2010, na Escola Municipal José Vanderlei Mayer, situada no bairro de Vila Nova Alvorada. Foram realizadas duas oficinas, envolvendo dois grupos de educadores, com encontros semanais de 4 horas de duração em cada grupo, durante 13 semanas. Os encontros aconteceram às terças-feiras (grupo 1) e às quartas-feiras (grupo 2), no período noturno (18h às $22 \mathrm{~h}$ ). O grupo formado por professores, servidores técnicoadministrativos de escolas públicas e merendeiras detinha, de modo geral, pouco conhecimento sobre essa arte. Dentre os inscritos, com idades entre 20 e 50 anos, houve uma maioria de mulheres (80\%), formando assim dois grupos heterogêneos.

As oficinas foram divididas em etapas. A primeira foi dedicada à (re)descoberta da sombra, com o objetivo de despertar o interesse dos participantes. Em seguida, passamos a explorar diversos materiais na criação de cenas, juntamente com o estudo de aspectos técnicos e históricos, aprofundando o conhecimento sobre essa arte.

\footnotetext{
1 Mestre em Artes. Professor do Instituto Federal de Educação de Santa Catarina - Campus Araranguá. E-mail: emerson.cardoso@ifsc.edu.br. Fone: (48) 96033259

2 Doutorando do PPG em Ciências da Linguagem - Unisul. Professor do Instituto Federal de Educação de Santa Catarina - Campus Araranguá. E-mail: cremilson.ramos@ifsc.edu.br. Fone: (48) 99169167

3 As oficinas fizeram parte da pesquisa de mestrado intitulada "A (re)descoberta da sombra: experiência realizada com educadores na cidade de Imbituba - SC.", apresentada ao Programa de Pós-graduação em Teatro na Universidade do Estado de Santa Catarina - UDESC. 
Finalmente realizamos a montagem e apresentação do trabalho final, inspirado no conto A pequena vendedora de fósforos de Hans Christian Andersen (1805-1875).

Essas divisões do trabalho se interpenetraram, revelando especificidades, descobertas e desafios. No entanto, serão destacados aqui apenas os aspectos relacionados à ideia de silêncio e o sentido de experiência na prática com o teatro de sombras.

Optamos por denominar "experiência" as atividades realizadas com os dois grupos de educadores, considerando a singularidade do envolvimento de cada participante nas oficinas e, principalmente, pela peculiaridade dos relatos4 e depoimentos descritos por eles. "A experiência pode ser definida como "o que nos acontece, o que nos toca. [...] A cada dia se passam muitas coisas, porém, ao mesmo tempo, quase nada nos acontece" 5 . Assim, diante das mudanças e do tempo acelerado da vida moderna, a "experiência" poderia nos auxiliar a estabelecer relações significativas entre os indivíduos, os objetos (ferramentas) e o mundo.

Walter Benjamim6 relaciona essas características culturais à pobreza da experiência do homem moderno quando diz que "Cada manhã recebemos notícias de todo o mundo. E, no entanto, somos pobres em histórias surpreendentes." No contexto das oficinas, foi fundamental criar condições para que as práticas realizadas promovessem a "experiência" no seu sentido mais amplo. A experimentação, o estudo teórico e a reflexão sobre as vivências e acontecimentos auxiliaram para que as experiências adquirissem outros significados e sentidos. Portanto, priorizamos uma metodologia que estimulasse o diálogo entre teoria e prática, num permanente movimento entre criar, fazer, experimentar, refletir, praticar e estudar. Esses

\footnotetext{
${ }^{4}$ Optamos por utilizar apenas as iniciais dos nomes dos participantes para identificar os depoimentos coletados e as impressões relatadas.

${ }^{5}$ LARROSA, Jorge Bondía. Notas sobre a experiência e o saber de experiência. In: Revista Brasileira de Educação, 2002, p. 21.

${ }^{6}$ BENJAMIN, Walter. Magia e Técnica, Arte e Política, 1986, p. 203.

Revista "O Teatro Transcende" Departamento de Artes - CCEAL da FURB - ISSN 2236-6644 - Blumenau, Vol. 20, No 1, p. 74 -93, 2015
} 
procedimentos serviram para promover a participação, a relação entre os participantes e também a encenação. Contudo, destacamos que não há métodos que garantam resultados totalmente satisfatórios.

Fazer teatro de sombras, uma arte tradicionalmente artesanal, é um desafio, pois ao mesmo tempo em que exige a escuridão, também nos desperta para outro modo de olhar o que nos cerca. A sombra traz consigo uma série de significados, comumente atribuídos ao desconhecido, ao lado negativo e ao inconsciente. Para os que vivenciam essa arte, as sombras, que outrora passavam "despercebidas", destacam-se, despertam os sentidos, começam a figurar outra realidade. Praticar essa arte pode surpreender aqueles que, intencionalmente, desejam investigar acontecimentos diferenciados. Essa é condição fundamental ao "ato de pensar" que, segundo John Dewey7, agrega uma dimensão de questionamentos, de não conformidade com a situação apresentada. Isso é parte daquilo que o autor nomeia de "experiência” no seu caráter emancipatório e educativo.

Ainda de acordo com Dewey8, todo sujeito é resultante das experiências que constrói. De forma intencional ou não, o acontecimento da mesma faz parte do desenvolvimento do indivíduo, auxilia-o a construir conhecimento e a movimentar-se no meio em que vive. É na interação com o meio social, com outros objetos e indivíduos, que ele consegue estabelecer relações e situações de "construção de conhecimento" e "significados". E esses têm, assim, a finalidade de produzir sentido para a experiência.

A interação entre homem, ambiente, situação e ferramentas faz com que esses se modifiquem reciprocamente, destacando a necessidade da experiência. Assim,

\footnotetext{
${ }^{7}$ DEWEY, John. Como pensamos: como se relaciona o pensamento reflexivo com o processo educativo, 1959 a.

${ }^{8}$ Idem, Experiência e educação, 1971.

Revista "O Teatro Transcende" Departamento de Artes - CCEAL da FURB - ISSN 2236-6644 - Blumenau, Vol. 20, № 1, p. 74 -93, 2015
} 
experiência "é a continua interação do homem com o ambiente, por meio do qual ele cresce e ao mesmo tempo modifica a própria natureza."9

Essas ideias, vivenciadas na prática do teatro de sombras com educadores, levaram-nos a compreender os significados da experiência, relacionando-a a outra forma de conhecer o próprio sujeito e a arte teatral. Assim, comunicar o que se experimentou e se viveu pode ser também compreendido como um processo de reconstrução e reorganização da experiência. Essa contínua organização e reconstrução dos conhecimentos construídos e compartilhados tem por fim melhorar o que se viverá futuramente.

As oficinas primeiramente oportunizaram o silêncio, como forma dos participantes percebê-lo como elemento cênico, ou seja, uma pausa na correria cotidiana para se perceberem no espaço, no aqui e agora, ouvirem suas necessidades e se conectarem com suas memórias e experiências - um estímulo para redescobrirem as sombras e as nuances entre claro e escuro, luz e escuridão.

Também foi estimulado o diálogo, como forma de cada um compartilhar as suas descobertas e dificuldades. Outro procedimento que auxiliou no desenvolvimento dos trabalhos e da pesquisa foram os momentos destinados à realização de desenhos, anotações escritas e registros fotográficos das impressões sobre a (re)descoberta da sombra.

A ideia de "(re)descoberta" envolve o princípio de descobrir e redescobrir as sombras para a prática teatral. O termo engloba o sentido de ver e perceber as sombras de outro modo, não habitual. Todo ser humano dotado de visão conhece a

\footnotetext{
${ }^{9}$ SCHMITZ, Egídio Francisco. O pragmatismo de Dewey na educação: esboço de uma filosofia da educação, 1980, p. 24. 
sombra e a vê; porém, no teatro, olhar para as sombras, observar suas formas, mudanças e transformações, supera o ato de apreciar - busca-se compreendê-las como elemento artístico.

Para a participante FP, as atividades direcionadas para a (re)descoberta da sombra revelaram que:

Cada um é único. Fazer esse trabalho foi uma viagem pra mim. Lembrei com as sombras projetadas de coisas da minha infância e da vida adulta, teve momentos que me emocionei, não de tristeza, mas por algo que senti, não sei se foi por causa da música ou pelo momento [...]. Eu não entendo muito de arte, mas arte pra mim é isso; é imaginação, e quando acordamos parece que vemos as coisas de um jeito diferente.

"(Re)descobrir" a sombra para o teatro implicou conhecer suas possibilidades técnicas, expressivas, poéticas e filosóficas. Exigiu conhecê-la como linguagem cênica um convite à reflexão sobre o incorpóreo, o efêmero, e, portanto, à imaginação e à criação artística, como observou a participante IG: "o que seria de nós se não houvesse a luz ou a escuridão? A luz é tão importante para o teatro de sombras quanto as sombras".

Nas oficinas, precisou-se desenvolver um olhar atento, na medida em que as sombras e a luz despertaram não somente a imaginação como uma série de sensações e lembranças, conforme destacou a participante SC:

É um desafio estar aqui. Quando criança, eu brincava com as sombras à luz de vela e minha mãe dizia que não era bom, porque elas eram coisa do mal. Minha mãe era muito religiosa. Um dia, acho que de tanto ela falar, eu vi uma mão de sombra vir para cima de mim na cama e até hoje eu tenho muito medo do escuro e das sombras. Hoje, ainda não consigo dormir com o quarto todo escuro, eu preciso deixar uma luz sempre acesa. 
As sombras evocaram lembranças e opiniões, muitas relacionadas com princípios que são rejeitados porque relacionam a sombra a conceitos negativos, ao contrário da luz, que geralmente representa o lado positivo das coisas. Articular as experiências e impressões dos participantes com o teatro de sombras foi, como diria Montecchi10, uma tarefa ainda "estranha" a nossa cultura. Para a participante AS:

\begin{abstract}
Imaginei e senti muita coisa! É curioso como as mãos passam a ser nossos olhos junto com os ouvidos. As partes do corpo que mais senti no escuro para mim foram o rosto e abdômen. Os meus pés pareciam que tinham perdido o chão no escuro e até o meu jeito de andar mudou. No escuro outros sentidos aparecem. Tudo passa a fazer muito barulho, a respiração fica mais presente, a pele parece que fica mais sensível e os ouvidos ficam alerta. É uma forma diferente de desenvolver nossa sensibilidade. Ficamos alerta para tudo o que pode acontecer.
\end{abstract}

Foi preciso que os participantes se habituassem ao escuro e ao silêncio, percebendo outras formas de lidar com o corpo e os sentidos. Eles avaliaram essa etapa das oficinas como "um trabalho que mostra nossa sensibilidade - que parece perdida na correria do dia a dia" (RG). Ou seja, o teatro de sombras possibilitou o que Larrosa11 aponta como indispensável à experiência: um "parar para pensar, parar para olhar, parar para escutar, "demorar-se nos detalhes", "cultivar a atenção e a delicadeza, abrir os olhos e os ouvidos, falar sobre o que nos acontece", "cultivar a arte do encontro" e principalmente "ter paciência e dar-se tempo e espaço.".

Os trabalhos nos grupos 1 e grupo 2 evidenciaram também que não damos muita importância para a sombra, o silêncio ou para os detalhes na vida cotidiana. De acordo com a participante AP, "a sombra parece estar mais em evidência no verão, quando procuramos uma sombra para nos proteger do sol. Sempre que vou à praia a primeira coisa que penso é: onde está a sombra?". Também concluíram que as

\footnotetext{
${ }^{10}$ MONTECCHI, Fabrizio. Viagem pelo reino da sombra. In: BELTRAME, Valmor (Org.). Teatro de Sombras: técnica e linguagem, 2005, p. 25.

${ }^{11}$ LARROSA, Jorge Bondía. Notas sobre a experiência e o saber de experiência. In: Revista Brasileira de Educação, 2002, p. 21. 
sombras cotidianas projetadas no chão podem ser interessantes para se estudar suas formas e especificidades, mas não servem para o teatro, já que as deformações e os efeitos, propositalmente criados com as sombras na tela vertical de tecido, são mais interessantes: "uma sombra no chão é comum, já as sombras na tela são criadas e é por isso que elas são interessantes. O que mais chamou a minha atenção foi a sombra dos objetos porque, na tela, me fizeram imaginar muitas coisas" (FS).

Cada participante encontrou nas sombras, ou melhor, visualizou na tela, imagens e sentidos que, de certa forma, estavam conectadas com a memória e que, através da percepção do silêncio como elemento cênico e do estímulo a reflexão sobre a prática, foram reorganizadas, ou seja, passaram a fazer sentido não só como meras imagens, mas como teatro. Em ambos, no ator-animador e no espectador, existiu um ato de recriação, de compreensão do que foi significativo, fazendo assim destacar-se a experiência.

De acordo com Dewey12, “Aprender da experiência é fazer uma associação retrospectiva e prospectiva entre aquilo que fazemos às coisas e aquilo que, em conseqüência, essas coisas nos fazem gozar ou sofrer." No entanto, para o autor, "a simples atividade não constitui experiência, pois a experiência vai além, é mais complexa. O que caracteriza a "experiência" é a necessidade de uma "reflexão" e as consequências por ela provocadas. A atividade, "se não for percebida como a conseqüência de outra ação", adquirindo significação perante o sujeito que a praticou, não pode ser denominada como "experiência".

Dewey13 afirma que "o princípio de continuidade de experiência significa que toda e qualquer experiência toma algo das experiências passadas e modifica de algum modo as experiências subseqüentes". O valor de uma experiência varia na medida em

\footnotetext{
${ }^{12}$ DEWEY, John. Democracia e Educação, 1959b, p. 152-153.

${ }^{13}$ DEWEY, John. Experiência e educação,1971, p. 26.

Revista "O Teatro Transcende" Departamento de Artes - CCEAL da FURB - ISSN 2236-6644 - Blumenau, Vol. 20, № 1, p. 74 -93, 2015
} 
que esse "continuum experiencial" proporcione relações significativas para o sujeito, no decorrer de sua vida.

Para os educadores, as oficinas se mostraram como um espaço destinado ao encontro, ao observar, ao ouvir os outros, ao sentir o que nos acontece - já que consideraram a prática teatral como uma forma de enriquecer as vivências pessoais e também de compreensão do outro - numa relação mútua de transformação e conhecimento por meio da experiência. Conforme o trabalho foi sendo realizado, as relações estabelecidas foram se modificando, alterando o sentido das práticas para além das oficinas.

Outros aspectos relativos à "experiência" também foram considerados, como o temor que o escuro despertou em alguns participantes: "Quando entrei na sala com pouca luz me senti sufocada; o escuro me assusta e me deprime. Esse foi o motivo que me fez desistir da oficina" (RG); a mesma sensação foi compartilhada pela participante AC: "No escuro eu me sinto sempre em perigo; é como se algo fosse me pegar ou me atingir. Não consigo ficar calma sem poder ver tudo ao meu redor". O medo do escuro foi uma das questões que precisou ser resolvida logo de início - mesmo se tratando de um trabalho com adultos. Portanto, desenvolver atividades de ambientação e familiarização com o escuro foi imprescindível.

Paradoxalmente às afirmações sobre o medo do escuro, a participante VP declarou que: "a escuridão me traz paz. Depois da oficina chego em casa me sentindo bem e fico pensando em tudo o que fizemos; às vezes chego até a sonhar". Percebe-se que para a participante JR, não foi diferente: "eu senti uma sensação de liberdade porque ninguém estava me vendo". Essas impressões nos remeteram ao "sentido da experiência" em Dewey. 
Para o autor14, a vida é repleta de diferentes tipos de percepção e de experiências, e essas, sejam positivas ou negativas, necessariamente modificam nossa atitude frente a outras experiências. Porém, "toda experiência modifica quem a faz e por ela passa e a modificação afeta, quer o queiramos ou não, a qualidade das experiências subseqüentes, pois é outra, de algum modo, a pessoa que passar por essas novas experiências." Dessa forma, podemos observar em outro depoimento da participante RG, que, apesar da insegurança que o escuro the trouxe, ela soube ressignificar suas impressões:

\begin{abstract}
Mesmo agoniada, o escuro me fez olhar para dentro de mim, pois trabalhar com as sombras parece primeiramente um encontro consigo mesmo. No dia a dia, não damos importância para ela, mas, na oficina, ela me mostrou um pouco mais quem sou. Não temos tempo para nós, ou para nos ouvir, estou acostumada com uma vida corrida e acho que não consigo ficar mais parada. Acho que agora as sombras não serão mais as mesmas pra mim.
\end{abstract}

Por meio do depoimento de RG, consideramos, de acordo com Dewey15, que nem toda "experiência" por que passamos é necessariamente "prazerosa" ou "educativa'. "É deseducativa toda experiência que produza o efeito de parar ou destorcer o crescimento para novas experiências posteriores". Para o autor, esse caráter "deseducativo" está relacionado ao crescimento e desenvolvimento humano: “Uma experiência pode ser tal que produza dureza, insensibilidade, incapacidade de responder os apelos da vida, restringindo, portanto, a possibilidade de futuras experiências mais ricas". Assim, é possível considerar que a experiência "poderá aumentar a destreza em alguma atividade", mas "de tal modo que habitue a pessoa a certos tipos de rotina, fechando-Ihe o caminho para experiências novas." Por meio da qualidade dessas situações, é possível construir conhecimentos para outras aprendizagens ou até tornar-se alheio às situações que favoreceriam a construção de conhecimentos futuros. Por outro lado, "as experiências podem ser tão desconexas e desligadas umas das outras que, embora agradáveis e mesmo excitantes em si

\footnotetext{
${ }^{14}$ Ibidem, p. 26.

${ }^{15}$ DEWEY, John. Experiência e educação,1971, p. 14. Revista "O Teatro Transcende" Departamento de Artes - CCEAL da FURB - ISSN 2236-6644 - Blumenau, Vol. 20, № 1, p. 74 -93, 2015
} 
mesmas, não se articulam cumulativamente.". A experiência atua sobre as condições das experiências futuras, ou seja, toda experiência tem um lado ativo, que muda, de algum modo, o sujeito.

Trabalhar com pouca luz, valorizar os momentos de silêncio, o diálogo com as sombras e sons, despertou outras impressões, o que pode ser observado no depoimento da participante VP:

Sempre quis fazer teatro, mas sou muita tímida e só hoje, depois de tantos anos, vim participar de uma oficina de teatro e acabei me sentido protegida atrás da tela, porque assim posso me expressar sem os outros ficarem olhando diretamente pra mim - não pensei que isso fosse possível no teatro.

Observa-se também o resultado desse tipo de atividade na fala de IP: "A sala escura me ajudou a me desinibir, se tivesse tudo claro eu não faria o que fiz. [...] nesse teatro vi que é possível a gente não aparecer, foi por isso que quis participar".

Esses depoimentos corroboram a ideia de Éduard Limbos16, que afirma que o teatro de sombras pode estimular uma pessoa "tímida" que "não ousaria nunca exprimir-se em público", a "encontrar todos os seus meios ao abrigo da tela", ou seja, o ator se "esconde" atrás da tela para se revelar ao público, através das sombras como uma experiência singular.

De acordo com Montecchi17, "O espectador e o animador encontram-se através da sombra", e é exatamente na tela que seus olhares se cruzam. As sombras

\footnotetext{
${ }^{16}$ LIMBOS, Éduard. Théâtre d'ombres, 1992, p. 2.

${ }^{17}$ MONTECCHI, Fabrizio. Além da tela - Reflexões em forma de notas para um teatro de sombras contemporâneo, 2007, p. 74. 
tornam-se o foco do trabalho, o silêncio é valorizado quando surge, e o texto falado torna-se necessário apenas quando é essencial à ação dramática. Assim, a imagem é criada junto a sons e silêncio, sombras e luzes, despertando memórias e sentido às experiências pessoais e coletivas. Para os participantes mais "tímidos", esses elementos contribuíram para que expressassem opiniões e sentimentos, que talvez não demonstrassem se estivessem diretamente na cena diante do espectador. A princípio, era a sombra, ou seja, a personagem quem estava "falando", expressandose, quando na verdade era o ator quem estava "atuando".

Dessa forma, o ator que está aparentemente escondido se revela claramente na tela, conforme observou a participante AS: "É o lugar onde se realizam os sonhos". Isso evidenciou que a tela não é uma fronteira, e sim uma ponte entre o ator-animador e o espectador, ou seja, é o "lugar de confronto de nossas próprias projeções".18

Nas oficinas, as experimentações não se resumiram à realização e à repetição de "simples atividades", uma vez que "refletir" sobre as movimentações do corpo no espaço, observando as próprias sombras e as dos outros participantes (percebendo as deformações e transformações), possibilitou que emergisse a "experiência", porque o que foi percebido passou a ser recriado e encenado na tela, exigindo assim o envolvimento coletivo e a reflexão - como resultado do ato de vivenciar e (re)descobrir as sombras, (re)significando-as como conhecimento compartilhado na tela em forma de teatro.

Para a participante SC, a ideia de teatro se resumia a "presença do ator no palco." No entanto, ela descobriu a possibilidade da sombra projetada na tela como

\footnotetext{
${ }^{18}$ AMOROS, Luc. De la tradition à la modernité. In: DAMIANAKOS, Stathis. Théâtre d'ombres - tradition et modernité, 1986, p. 4.
} 
outra forma de compreender o teatro. Para a participante RV, que tinha uma vaga impressão sobre o teatro de sombras, também se abriu um leque de possibilidades:

Pensei que a palavra teatro queria dizer que existe um tipo de teatro, o teatro com atores na cena. Aqui na oficina de teatro de sombras percebi que existem outras possibilidades de se fazer teatro, como o teatro de bonecos. Tem também outras formas que a gente vê na TV e na Internet, como as máscaras ou até as sombras; [...] mas a gente acaba não relacionando com o teatro e sim com outra coisa.

Para os participantes que desconheciam o teatro de sombras, a ideia de "teatro" relacionava-se, exclusivamente, à presença do ator visível na cena. Outras linguagens teatrais, de acordo com RV, como o teatro de bonecos ou máscaras, estavam relacionadas às atividades recreativas, e não ao teatro e suas especificidades.

Nas oficinas foi notável o interesse dos participantes em fazer teatro, como destacou a participante AG: "Precisamos de mais iniciativas como essa, não queremos apenas cursos para professores; queremos sair, ver teatro, ir ao cinema, ter outras experiências". As oficinas foram, de certa forma, ao encontro do desejo dos participantes, que descobriram diversas possibilidades de se expressarem com as sombras. As sombras projetadas em diferentes telas também serviram como incentivo para aqueles que não imaginavam estar diretamente diante do público no palco.

Nesse sentido, foi fundamental recepcionar os participantes com a sala previamente preparada. A importância desse cuidado se manifesta no relato de FS, "Quando entrei na sala com essa penumbra e esse perfume de incenso, eu me esqueci de tudo lá fora. Eu nunca tinha imaginado fazer teatro no escuro. Isso me ajudou a entender melhor esse tipo de arte." Como relata o participante $\mathrm{CR}$, "O clima tranquilo me ajudou a me concentrar. O escuro e o silêncio me causam medo também, porque me lembram a solidão. Foi a música que me ajudou a explorar o espaço e a esquecer o medo". A música e as instruções dadas durante os trabalhos ajudaram a direcionar o Revista "O Teatro Transcende" Departamento de Artes - CCEAL da FURB - ISSN 2236-6644 - Blumenau, Vol. 20, No 1, p. 74 -93, 2015 
foco da atenção dos participantes para os problemas a serem resolvidos e os objetivos a serem alcançados. Dessa forma, até os que demonstraram certo receio do escuro se sentiram mais confiantes a realizarem as atividades. Segundo Vigotski19, "Ensinar o ato criador da arte é impossível; entretanto, isto não significa, em absoluto, que o educador não pode contribuir para a sua formação e manifestação". Assim sendo, foi fundamental preparar um ambiente que despertasse os sentidos e o envolvimento dos participantes - não através do excesso de estímulos, mas limitando-os apenas ao essencial, ou seja, a valorização da sombra e do silêncio como elementos indispensáveis da linguagem do teatro de sombras.

O princípio do "menos que representa mais" foi uma das propostas sugeridas no decorrer das oficinas. A organização minuciosa do espaço revelou que o teatro de sombras é uma arte que trabalha com precisão e síntese. Como observou a participante $C R$, “é preciso organização para se fazer esse teatro, pois tudo precisa estar muito bem organizado para a segurança de todos, já que a maior parte do trabalho é realizado na escuridão". Isso evidenciou, além da importância da disciplina na atividade teatral, as formas como os materiais e o ambiente influenciaram a criação das cenas e o desenvolvimento das oficinas.

Para Dewey20, os momentos capazes de envolver o sujeito em um processo de "reconstrução de experiências" podem ser geradores de oportunidades de aprendizagem e crescimento pessoal. Por isso, a preparação do ambiente pode ser entendida como um dos mecanismos para estimular e envolver o sujeito na experiência. De acordo com o autor21, as "condições internas" do indivíduo, relacionadas ao ambiente, aos materiais e situações "participam da experiência".

\footnotetext{
${ }^{19}$ VIGOTSKI, Lev Semyonovitch. Psicologia da Arte, 2001, p. 325.

${ }^{20}$ DEWEY, John. Experiência e educação, 1971, p. 71.

${ }^{21}$ Ibidem, p. 33.

Revista "O Teatro Transcende" Departamento de Artes - CCEAL da FURB - ISSN 2236-6644 - Blumenau, Vol. 20, № 1, p. 74 -93, 2015
} 
Assim, ficou comprovado que as condições externas influenciam e mudam as experiências subsequentes, pois "Há fontes fora do individuo que a fazem surgir." 22

As oficinas resultaram na apresentação de A pequena Vendedora de Fósforos, de Hans Christian Andersen, para o público, o que exigiu concentração, organização dos materiais e sintonia entre os participantes. A presença dos espectadores deu sentido ao trabalho realizado. Na avaliação do participante CR,

[...] no início eu não gostei muito desse tipo de teatro porque eu não aparecia na cena, então não era teatro pra mim. Em alguns momentos parecia uma forma de fazer cinema, projetando imagens. Com o passar do tempo eu entendi que é teatro sim, pois a gente atua e tem o espectador. Isso ficou claro na apresentação, pois mesmo sem ver o público eu o percebia através das risadas ou do silêncio que acontecia nas partes mais sérias. Na segunda apresentação foi diferente, pois eu mudei algumas coisas que não tinha dado certo.

Se as oficinas terminassem sem essa etapa, haveria, de certa forma, uma lacuna no trabalho realizado. A montagem e apresentação final possibilitaram uma reflexão mais aprofundada sobre os aspectos daquilo que "nos acontece" e passou a configurar o sentido do teatro e de experiência na contemporaneidade.

"O teatro talvez seja uma das artes mais difíceis porque requer três conexões que devem coexistir em perfeita harmonia: os vínculos do ator com sua vida interior, com seus colegas e com o público" 23. Nesse sentido, foi possível evidenciar as oficinas como práticas que relacionam o encontro coletivo ao fazer teatral, aonde os sujeitos vão para experimentar e vivenciar outras sensações, conhecer histórias e

\footnotetext{
${ }^{22}$ DEWEY, John. Experiência e educação, 1971, p. 31.

${ }^{23}$ BROOK, Peter. A Porta Aberta: reflexões sobre a interpretação e o teatro. Trad. Antonio Mercado. Rio de Janeiro, Civilização Brasileira, 2002, p. 26.
} 
principalmente compreender essas questões através da arte teatral, de forma que esse instante seja capaz de integrar e transformar as relações. Portanto, o teatro, enquanto proposta de educação pode estimular e desenvolver o sentido de experiência, ampliando a compreensão do indivíduo e da realidade, por meio de um processo consciente de expressão e comunicação.

A prática do teatro de sombras revelou que as necessidades e interesses de cada participante são singulares, ou seja, cada um possui formas de se expressar e de interpretar os acontecimentos, de acordo com as suas vivências, experiências e memórias. No entanto, a forma como cada um se apresenta não está cristalizada e nem é imutável, mas está aberta a outras práticas e descobertas.

A realização das oficinas com educadores gerou a expectativa de disseminação dessa arte, contribuindo para a formação dos participantes.

As atividades desenvolvidas estimularam a experimentação do uso de focos, de telas, silhuetas recortadas em papel cartão, de objetos e da sombra corporal como forma de praticar e compreender o teatro de sombras. No entanto, é possível afirmar que a experiência construída coletivamente possibilitou a produção de conhecimentos para a formação pessoal, profissional e artística dos participantes.

O percurso trilhado se fundamentou na perspectiva de que fazer teatro é uma atividade coletiva, essencial para o desenvolvimento do indivíduo, na medida em que valorizou as vivências pessoais e ampliou o sentido das relações. 
Com contribuições de John Dewey24, foi possível constatar que experiência é a relação que se processa entre os elementos e que, após o contato inicial, ocorrem alterações nos envolvidos. Tornou-se evidente que a experiência proporcionou alterações simultâneas entre os participantes e o que foi produzido. As duas partes se modificaram, pois as relações entre elas se alteraram.

$\mathrm{Na}$ trajetória dos dois grupos, cada etapa do trabalho foi compreendida como prática do Teatro de Sombras e não como um conjunto de técnicas criadoras de exibição de imagens. A sombra, a tela, as fontes luminosas e os recursos de animação foram meios usados para despertar a imaginação e os sentidos.

Analisar o sentido dessa experiência, considerando o contexto, suscitou reflexões sobre a prática teatral como processo no qual o indivíduo deve ser incentivado a interagir com a arte, na perspectiva de que isso possa contribuir para enriquecer suas experiências. O trabalho ampliou nosso olhar e apreço sobre as práticas intrínsecas à teoria, como oportunidades ímpares que colaboram para dar intensidade e qualidade às relações. As oficinas com educadores revelaram que é possível provocar o estranhamento do cotidiano, como forma de repensar o dia a dia por meio da arte.

Walter Benjamin25 alerta que a grande dificuldade de trocar experiências em nossos dias resulta do isolamento do indivíduo, pois "onde há experiência no sentido estrito do termo entram em conjunção a memória, certos conteúdos do passado individual com outros do passado coletivo". Deparar-se com questões como essa foi um desafio que enriqueceu a (con)vivência durante os meses de trabalho e serviu de

\footnotetext{
${ }^{24}$ Principalmente sua obra Experiência e educação, de 1971.

${ }^{25}$ BENJAMIN, Walter. Magia e Técnica, Arte e Política, 1986, p. 107.
} 
estímulo para diminuir as nossas "distâncias" e diferenças. É verdade que boa parte dos educadores que iniciaram as oficinas abandonou o grupo, mas esse foi outro desafio compreendido e superado.

Certamente a experiência aqui descrita não se revela como ela verdadeiramente aconteceu, e sim como ela foi lembrada por quem a vivenciou, sentiu, e, por isso, sua relevância está contida no tecido da rememoração. A organização dessa memória foi importante como registro capaz de estimular outras iniciativas.

Importante é a experiência individual também ter sentido no contexto coletivo. Nessa perspectiva, a montagem da peça e os caminhos permeados por desafios e dificuldades para se chegar a ela também contribuíram para o amadurecimento e crescimento pessoal, uma vez que os participantes atribuíam sentido às práticas realizadas.

Com as apresentações do trabalho final, também percebemos, fazendo uso da ideia de Paulo Freire26, que "ensinar não é transferir conhecimento, mas criar as possibilidades para a sua produção ou a sua construção". Por isso, além do conhecimento histórico e dos princípios técnicos da linguagem do teatro de sombras, foi priorizado espaço para a expressão individual e coletiva e também a sistematização dos saberes produzidos.

Nesse contexto, a prática teatral torna-se efetiva pela multiplicidade de ideias e lembranças que despertam, (re)significando as experiências. O teatro pode promover mudanças quando ocorre a familiarização com os códigos teatrais e sua história,

\footnotetext{
${ }^{26}$ FREIRE, Paulo. FREIRE, Paulo. Pedagogia da autonomia. São Paulo: Paz e Terra, 2002.
} 
aliados à reflexão sobre a prática, já que a experiência pressupõe o contato com a realidade vivida pelo sujeito.

A experiência compartilhada com os grupos de educadores, além de promover a compreensão dessa manifestação artística, aponta a necessidade de nos tornarmos mais humanos através do sentido de experiência no mundo caótico em que vivemos. No entanto, o que sentimos quando surge o silêncio? Observamos que quase sempre procuramos evitá-lo no dia a dia, principalmente nos momentos de lazer ou recreação, talvez por tentarmos evitar o que na opinião de Perdigão27 poderia ser apontado como "silêncio existencial", ou seja, a recusa da solidão e da morte. O que podemos destacar a partir do trabalho realizado é que o diálogo propostos entre sombras e silêncio pode resultar em criatividade, reflexão e comunicação, que remontam as nossas memórias pessoais e coletivas - elementos organizadores e transformadores de conhecimentos e experiências.

\section{REFERÊNCIAS}

AMOROS, Luc. De la tradition à la modernité. In: DAMIANAKOS, Stathis. Théâtre d'ombres - tradition et modernité. Trad. Valmor Beltrame. Charleville-Mézières: Institut International de la Marionnette, 1986.

\footnotetext{
${ }^{27}$ PERDIGÃO, Andréia Bonfim. Sobre o silêncio, 2005.
} 
BENJAMIN, Walter. Magia e Técnica, Arte e Política. Trad. Paulo Sérgio Rouanet. São Paulo: Brasiliense, 1986.

BROOK, Peter. A Porta Aberta: reflexões sobre a interpretação e o teatro. Trad. Antonio Mercado. Rio de Janeiro, Civilização Brasileira, 2002.

DEWEY, John. Como pensamos: como se relaciona o pensamento reflexivo com o processo educativo. Trad. Haydée de Camargo Campos. São Paulo: Nacional, 1959a.

Democracia e Educação. Trad. Godofredo Rangel e Anísio Teixeira. São Paulo: Nacional, 1959b.

. Experiência e educação. Trad. Anísio Teixeira. São Paulo: Nacional, 1971.

Vida e educação. Trad. Anísio Teixeira. São Paulo: Melhoramentos, 1978.

FREIRE, Paulo. Pedagogia da autonomia. São Paulo: Paz e Terra, 2002.

LARROSA, Jorge Bondía. Notas sobre a experiência e o saber de experiência. Trad. João Wanderley Geraldi. In: Revista Brasileira de Educação. Jan/Fev/Mar/Abr 2002, no 19.

LIMBOS, Éduard. Théâtre d'ombres. Trad. Eliane Lisboa. Paris: Fleurus Idées, 1992. 
MONTECCHI, Fabrizio. Além da tela - Reflexões em forma de notas para um teatro de sombras contemporâneo. Trad. Adriana Aikawa da Silveira Andrade. In: Móin -Móin: Revista de Estudos sobre Teatro de Formas Animadas. Jaraguá do Sul: SCAR/UDESC, ano 3, v. 4, 2007.

. Viagem pelo reino da sombra. Trad. Valmor Beltrame. In:

BELTRAME, Valmor (Org.). Teatro de Sombras: técnica e linguagem. Florianópolis: UDESC, 2005.

PERDIGÃO, Andréia Bonfim. Sobre o silêncio. São Paulo: Pulso Editorial, 2005.

SCHMITZ, Egídio Francisco. O pragmatismo de Dewey na educação: esboço de uma filosofia da educação. Rio de Janeiro: Livros Técnicos e Científicos, 1980.

VIGOTSKI, Lev Semyonovitch. Psicologia da Arte. Trad. Paulo Bezerra. São Paulo: Martins Fontes, 2001. 